\title{
Adult Neurogenesis, Mental Health, and Mental Illness: Hope or Hype?
}

\author{
Amelia J. Eisch, ${ }^{1}$ Heather A. Cameron, ${ }^{2}$ Juan M. Encinas, ${ }^{3}$ Leslie A. Meltzer, ${ }^{4}$ Guo-Li Ming, ${ }^{5}$ and \\ Linda S. Overstreet-Wadiche ${ }^{6}$ \\ ${ }^{1}$ Department of Psychiatry, University of Texas Southwestern Medical Center, Dallas, Texas 75390-9070, ${ }^{2}$ Unit on Neuroplasticity, Mood and Anxiety \\ Disorders Program, National Institute of Mental Health, National Institutes of Health, Bethesda, Maryland 20892, ${ }^{3}$ Cold Spring Harbor Laboratory, Cold \\ Spring Harbor, New York 11724, ${ }^{4}$ Department of Bioengineering, Stanford University, Stanford, California 94305-5435, ${ }^{5}$ Johns Hopkins University, \\ Departments of Neurology and Neuroscience, Baltimore, Maryland 21205, and ${ }^{6}$ Department of Neurobiology, University of Alabama at Birmingham, \\ Birmingham, Alabama 35294
}

Psychiatric and neurologic disorders take an enormous toll on society. Alleviating the devastating symptoms and consequences of neuropsychiatric disorders such as addiction, depression, epilepsy, and schizophrenia is a main force driving clinical and basic researchers alike. By elucidating these disease neuromechanisms, researchers hope to better define treatments and preventive therapies. Research suggests that regulation of adult hippocampal neurogenesis represents a promising approach to treating and perhaps preventing mental illness. Here we appraise the role of adult hippocampal neurogenesis in major psychiatric and neurologic disorders within the essential framework of recent progress made in understanding "normal" adult neurogenesis. Topics addressed include the following: the life cycle of an adult hippocampal stem cell and the implications for aging; links between learning and hippocampal neurogenesis; the reciprocal relationship between cocaine self-administration and adult hippocampal neurogenesis; the role of adult neurogenesis in an animal model of depression and response to antidepressant exposure; the impact of neonatal seizures on dentate gyrus neurogenesis; and the contribution of a schizophrenia-susceptibility gene to adult hippocampal neurogenesis. These topics are discussed in light of the regulation of adult neurogenesis, the relationship to normal neurogenesis in adulthood and aging, and, importantly, the manipulation of neurogenesis to promote mental health and treat mental illness.

Key words: neural stem cell; epilepsy; learning; depression; addiction; schizophrenia

\section{Introduction}

Arguably one of the most exciting scientific findings of the past 50 years is the discovery that discrete brain regions make new neurons throughout life. The hippocampus is a major site of adult neurogenesis, a process in which hippocampal stem cells (HSCs) in the subgranular zone (SGZ) and their offspring give rise to mature, functionally integrated granule cell neurons (Kempermann et al., 2004; Abrous et al., 2005) (Fig. 1). Research on the mechanisms that control progression through these dynamic stages, HSC to mature granule cell, as well as the electrophysiological development of cells in each stage indicates the impor-

Received Aug. 11, 2008; revised Sept. 8, 2008; accepted Sept. 9, 2008.

This work was supported by National Institute on Drug Abuse Grants R01 DA016765 and K02 DA023555 (A.J.E.) National Institutes of Health Grants NS0488271 and MH084018 (G.L.M.), Intramural Research Program of the National Institute on Mental Health Grant Z01-MH002784 (H.A.C.), a National Alliance for Research on Schizophrenia and Depression Young Investigator Award (J.M.E.), a Stanford Bio-X Graduate Fellowship (L.A.M.), a Klingenstein Fellowship Award in the Neurosciences, the March of Dimes, the Alfred P. Sloan Foundation and Adelson Medical Research Foundation (all to G.L.M.), and the Epilepsy Foundation (L.S.O.-W.). A.J.E. thanks Dr. Diane Lagace, Nathan DeCarolis, Michele Noonan, Dr. Shveta Malhotra, and her coauthors for their significant intellectual contributions to this article during its preparation. A.J.E. particularly acknowledges the skill and effort of Jessica L. Ables in crafting Figure 1.

Correspondence should be addressed to Dr. Amelia J. Eisch, Department of Psychiatry, University of Texas Southwestern Medical Center, Dallas, TX 75390-9070. E-mail: amelia.eisch@utsouthwestern.edu.

L. A. Meltzer's present address: iZumi Bio Inc., 855 Maude Avenue, Mountain View, CA 94043.

D01:10.1523/JNEUROSCI.3798-08.2008

Copyright $\odot 2008$ Society for Neuroscience $\quad 0270-6474 / 08 / 2811785-07 \$ 15.00 / 0$ tance of both intrinsic properties of the cell as well as the SGZ microenvironment.

Several lines of evidence suggest that adult hippocampal neurogenesis is important in psychiatric and neurologic disorders, such as addiction, depression, epilepsy, and schizophrenia. For example, the hippocampus is important in memory and mood regulation and can have major influence over the reward pathway of the brain (Kelley et al., 1982; Groenewegen et al., 1987; Amaral and Witter, 1989; Totterdell and Smith, 1989; Floresco et al., 2001b). Hippocampal structure and function are dysregulated in the brains of patients with schizophrenia, addiction, epilepsy, and mood disorders (Sapolsky, 2000; Antonova et al., 2004; Geuze et al., 2005; Lucassen et al., 2006; Keller and Roberts, 2008). Moreover, adult neurogenesis is altered in animal models of these disorders, and effective therapies often normalize these changes (Chen et al., 2000; Malberg et al., 2000; Eisch, 2002; Abrous et al., 2005; Pittenger and Duman, 2008). Although current findings in the field suggest that adult hippocampal neurogenesis is not a sole cause of these illnesses or the sole mechanism of treatment efficacy, it is likely an important contributor to these complex disorders.

As exciting as the putative links between hippocampal neurogenesis and neuropsychiatric disorders appear, there exist major gaps in our understanding. Here six young investigators use a variety of approaches to identify and address key questions in the 


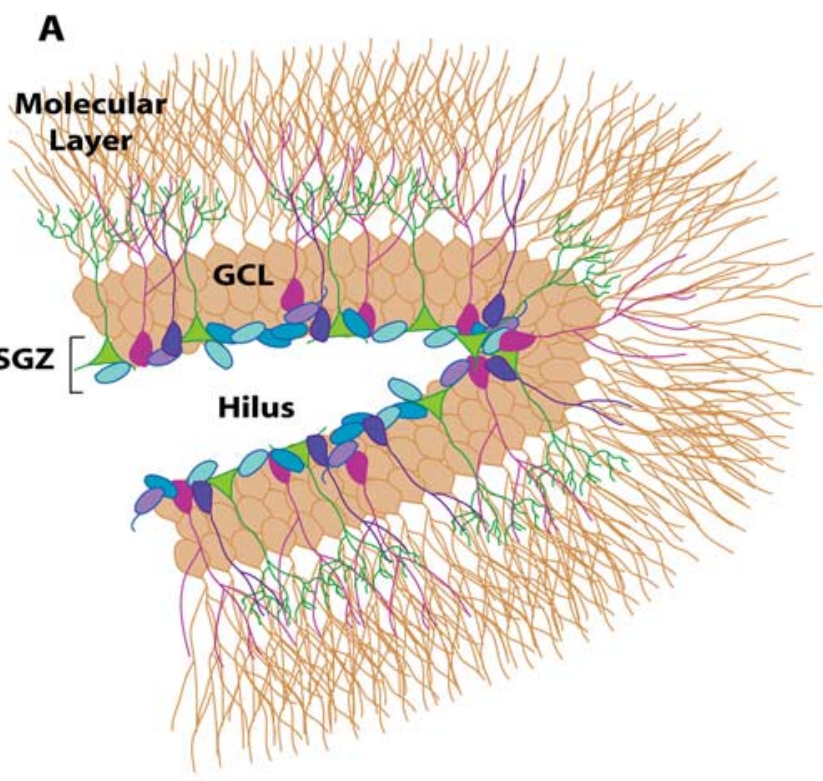

B

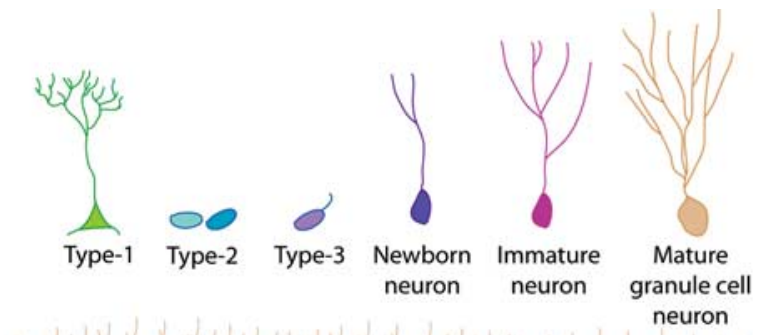

C

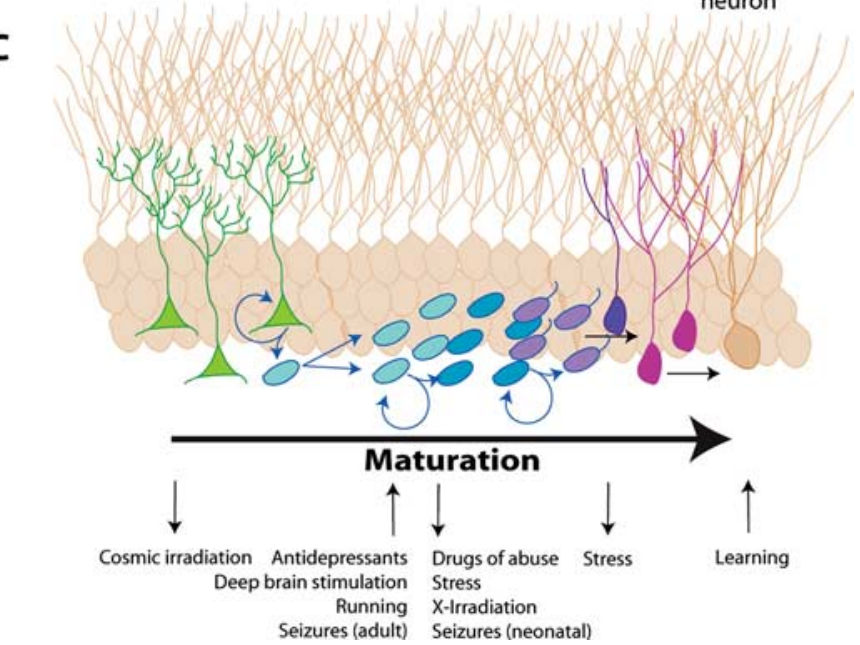

Figure 1. Stages of adult hippocampal neurogenesis. $\boldsymbol{A}$, The SGZ straddles the border of the hippocampal dentate gyrus granule cell layer (GCL) and hilus. The neurogenic SGZ contains cells at various stages of neurogenesis, which are individually shown in B. C, Cells in discrete stages of maturation are differentially influenced by pharmacological and physiological stimuli. This list is not meant to be comprehensive but rather highlight stimuli discussed in this review. Figure by Jessica L. Ables.

field. In an attempt to desegregate discussion of normal and pathological neurogenesis, the first two sections explore questions relevant to normal aging and learning, and the last four sections explore, in turn, the relationship between adult neurogenesis and addiction, depression, seizure disorders, and schizophrenia.

\section{The life cycle of an adult hippocampus neural stem cell: implications for aging}

As noted, adult hippocampal neurogenesis is a process consisting of many stages (Kempermann et al., 2004) (Fig. 1). Translational hope for neurogenesis will require detailed knowledge about factors that drive or slow this process. Several novel transgenic mouse lines have been used to specifically visualize discrete stages of neurogenesis from stem cell, to proliferation, differentiation, and eventual maturation (Yamaguchi et al., 2000; Mignone et al., 2004; Encinas et al., 2006; Lagace et al., 2007). Specifically, Type 1 HSCs are radial glia-like progenitors that divide at a low rate. Current research suggests that Type 1 cells divide asymmetrically to produce Type 2 cells, rapidly dividing (transient amplifying) progenitors that expand the precursor population and whose progeny differentiate into neuroblasts. These neuroblasts slowly maturate into granule cells, fully integrated into the hippocampal circuitry (Duan et al., 2008). Intriguingly, research suggests that discrete stages of the neurogenic process are a common target for regulation of neurogenesis by pharmacological and environmental stimuli. For example, a number of antidepressant-related stimuli, including fluoxetine, deep brain stimulation, and running, all enhance SGZ proliferation of the Type 2 cell (Kronenberg et al., 2003; Encinas et al., 2006; Toda et al., 2008). Although the convergence at this common stage of adult neurogenesis by such diverse manipulations is heartening for future efforts to independently manipulate neurogenesis, it is notable that major questions remain about the putative source of neurogenesis: the Type 1 HSC.

The main reason little is known about HSC regulation in vivo is that there are few tools to directly study or manipulate HSCs; being relatively quiescent, they cannot be thoroughly studied using standard methods such as the S-phase marker bromodeoxyuridine (Eisch and Mandyam, 2007). The lack of specific markers further complicates analysis, because HSC cells share markers with astroglial cells and neuronal precursor cells. However, using a transgenic mouse in which HSCs and precursors have nuclear labeling and thus are easily colabeled with other antibodies (Encinas et al., 2006), Encinas and colleagues have recently shown that Type 1 cell number is decreased by robust stimuli, such as cosmic radiation (Encinas et al., 2008). More recently they have tackled the question of what happens to HSCs during aging. Aging is among the most robust negative regulator of hippocampal neurogenesis. Based on the successful stimulation of neurogenesis in aged animals with environmental and pharmacological manipulations (Cameron and McKay, 1999), it has been postulated that age-mediated decline in neurogenesis is the result of a decline in the mitotic capabilities of HSCs (Hattiangady and Shetty, 2008). Using their mouse as shown previously (Encinas et al., 2006), Encinas and colleagues are now attempting to unveil the mechanism of the age-dependent decline in hippocampal neurogenesis.

This work by Encinas and colleagues is important because identification of the specific cell class responsible for the gradual loss of the ability to generate new neurons will allow researchers to cleanly restore or boost neurogenesis in the aged brain by means of particular stimuli with known specific cell targets. For instance, if Type 2 cells lose their mitotic capability with aging, perhaps antidepressants such as fluoxetine would allow restoration of neurogenesis in the aged dentate gyrus. Left unanswered 
for now is whether loss of hippocampal neurogenesis underlies age-induced cognitive decline, whether restoring neurogenesis translates into a beneficial cognitive and behavioral outcome, and whether the Type 1 cell is in fact a "true" stem cell. However, these findings are an important step toward understanding the potential link between neurogenesis, aging, and cognitive decline.

\section{Links between learning and adult hippocampal neurogenesis}

The function of adult-generated hippocampal neurons has been vigorously researched (and debated) in the past decade. Data primarily from correlational or ablation studies have given rise to controversial and sometimes inconsistent findings across laboratories and animal species (Shors et al., 2002; Zhao et al., 2008), but it appears that neurogenesis is important for at least some hippocampal-dependent memory tasks. More recent studies on the functional role of these cells have used immediate-early gene expression as a readout of activation of adult-generated neurons (Kee et al., 2007; Tashiro et al., 2007) or analysis of stabilization and removal of new neurons of different ages after a hippocampal-dependent learning task (Dupret et al., 2007). By showing the different responses of young cells as they mature, these recent studies highlight the power that can emerge from careful characterization studies. However, much remains unknown about the responses of new neurons to hippocampaldependent learning tasks and their contribution to hippocampal function.

To determine how learning activates young granule cells, Cameron and colleagues trained adult rats in a hippocampaldependent task, the Morris water maze, and examined the expression of immediate-early genes in adult-generated hippocampal neurons. They find that adult-generated neurons are activated during learning, and that this activation depends on the amount or strength of training as well as the variations in events during training. The data of Cameron and colleague data also add to the growing appreciation for regional differences in hippocampal function, showing, for example, that, after a single learning experience, the proportion of activated adult-generated granule cells is higher in the ventral dentate gyrus than in the dorsal dentate gyrus. Because the ventral hippocampus is closely linked to emotional memory and the dorsal hippocampus with spatial memory (Sahay and Hen, 2007), these data may suggest that adult-generated granule cells may be more involved in the more emotional, nonspatial aspects of hippocampal behaviors. Finally, Cameron and colleagues find that functional maturation of adult-generated granule cells occurs significantly faster in rats than in mice. This could be a key finding in explaining why electrophysiological data from mice and behavioral data from rats have sometimes appeared inconsistent.

The data from Cameron and colleagues showing the effects of hippocampus-dependent learning on the survival and maturation of adult-generated granule cells emphasize the complex relationship between learning, cell activation, and cell death. These data also urge additional consideration of the longitudinal or septotemporal axis, particularly because studies relevant to psychiatric disorders often reveal a septotemporal dependence in regulation of neurogenesis (Kim et al., 2005; Lagace et al., 2006).

\section{Addicted to neurogenesis: do new hippocampal neurons regulate cocaine self-administration?}

Adult hippocampal neurogenesis appears important for learning and memory, but its distinct contribution to memory formation, recall, or extinction remains to be clarified. The lack of studies on adult hippocampal neurogenesis and motivation is particularly notable, because neurogenesis is regulated by drugs of abuse (Eisch et al., 2000; Abrous et al., 2002; Nixon and Crews, 2002; Noonan et al., 2008) and the hippocampus influences both drugtaking and drug-seeking behaviors via its projections to limbic regions involved in reward (Taepavarapruk et al., 2000; Floresco et al., 2001a; Lodge and Grace, 2006).

To explore the relationship between neurogenesis and reward, Eisch and colleagues trained rats on a clinically relevant model of drug addiction, cocaine self-administration (CSA), and suppressed neurogenesis either before or after CSA via cranial irradiation (Snyder et al., 2005). Rats irradiated after CSA showed significantly increased drug-seeking behaviors in the context in which drug was previously taken and took more trials to extinguish responding than control rats. This suggests that adult neurogenesis may function to suppress the drug seeking elicited by drug-context memory. Rats irradiated before CSA took more cocaine compared with control rats and presented a vertical shift in the cocaine dose-response curve relative to controls, suggesting that they are more sensitized to cocaine. Interestingly, rats irradiated before CSA also had higher breakpoints on a progressive ratio schedule, suggesting that cocaine was more rewarding for them. Parallel experiments with a natural reward, sucrose pellet self-administration, found no differences between irradiated and control rats, suggesting that ablation of adult neurogenesis specifically influenced drug reward.

The data from Eisch and colleagues are the first to suggest that adult neurogenesis mediates aspects of drug addiction, such as the desire or memory for drug in drug-taking context, and the sensitivity to and reward received from cocaine taking. These data fit well both basic and clinical data, such as the altered proliferation and neurogenesis seen after many drugs of abuse, including nicotine, ethanol, opiates, and cannabinoids, and the strong propensity to relapse to drug taking in a drug-paired context (Eisch, 2002; Gould, 2006; Canales, 2007). In showing a possible function of adult neurogenesis in drug reward and drugcontext memory, these data urge continued consideration of the role of contextual cues in the treatment of addiction.

\section{The neurogenesis hypothesis of depression revisited: distinct roles for newborn neurons in the neurophysiology of depression and its treatment}

Of all psychiatric and neurologic disorders linked to adult hippocampal neurogenesis, mood disorders such as depression have received the most attention, as well as the most scrutiny. The initial excitement emerged from multiple lines of converging evidence connecting neurogenesis to mood disorders, most notably that stress (a precipitating factor in depression) decreases neurogenesis, whereas antidepressant treatment increases neurogenesis (Gould et al., 1997; Malberg et al., 2000). This led to the hypothesis that modulation of hippocampal neurogenesis is crucial to both the onset and treatment of depression, formalized as the "neurogenesis hypothesis of depression" (Drew and Hen, 2007). A corollary to this hypothesis is that hippocampal physiological and circuit dynamics somehow underlie affective behavior (Meltzer et al., 2005). The importance of adult-generated neurons to hippocampal circuit dynamics underlying depression and antidepressant efficacy is presumed but not well understood.

To address whether altered neurogenesis is important in depression and its treatment, Meltzer and colleagues used voltagesensitive dye imaging to probe hippocampal activity in a rodent model of depression and specifically the role of neurogenesis in depression-relevant neurophysiology and behavior (Airan et al., 2007b). Depression was modeled by exposing adult rats to the 
chronic mild stress paradigm (CMS), which over a period of 3 weeks induced a depression-like state characterized by increased immobility on the forced swim test. As with previous work using CMS (West and Weiss, 2005), the CMS-induced increase in immobility was reversed by treatment with the antidepressant fluoxetine. In acute brain slices from animals treated with CMS or antidepressant, Meltzer and colleagues identified dentate gyrus activity as a network-level endophenotype for depression-like behavior: evoked activity in the neurogenic dentate gyrus relative to the non-neurogenic area CA1 was downregulated by CMS and upregulated by antidepressant treatment. By quantifying neurogenesis in these rats, Meltzer and colleagues further explored the potential link between depression and neurogenesis. Intriguingly, and against the neurogenesis hypothesis of depression, CMS was not associated with a downregulation in neurogenesis, and ablation of neurogenesis did not induce a depression-like state. Conversely, and in support of the neurogenesis hypothesis of depression, antidepressant treatment increased neurogenesis. Using irradiation to ablate neurogenesis, Meltzer and colleagues also found that antidepressant behavioral efficacy required intact neurogenesis. Indeed, brief antidepressant treatment that was sufficient to transiently increase neurogenesis was also sufficient to exert behavioral effects long after drug clearance from the system, and this effect was absent in animals lacking neurogenesis.

The results presented by Meltzer and colleagues suggest that dentate gyrus activity predicts affective behavior in animal models of depression, a finding that may play an important part of the future of personalized diagnosis and treatment for depression (Holsboer, 2008). They further suggest that depression induction and treatment occur through distinct physiological mechanisms, with adult hippocampal neurogenesis required for the action of antidepressants in behaviors relevant to depression and anxiety (Santarelli et al., 2003) but apparently not involved in baseline mood determination.

\section{Seizing the network: integration of newborn neurons in epileptogenesis}

In addition to psychiatric disorders such as addiction and depression, neurologic disorders such as epilepsy have strong links to hippocampal structure and function in general and neurogenesis in particular (Parent, 2007). For example, seizure activity robustly enhances SGZ proliferation, leading to more adultgenerated neurons (Parent et al., 2006). In contrast to the adult, experimentally induced seizure activity in the neonate reduces SGZ proliferation (McCabe et al., 2001). These findings are particularly interesting because neonatal seizures appear to be associated with long-term effects on seizure sensitivity, cognition, and hippocampal volume (Holmes et al., 1998).

To address the short- and long-term consequences of neonatal seizure activity on dentate gyrus neurogenesis, OverstreetWadiche and colleagues used transgenic reporter mice given brief hypoxia-induced seizures or prolonged kainic acid-induced seizures at postnatal day 10 (P10). They found that both the brief and prolonged seizure activity reduced the number of newborn granule cells when examined 1 week later at P17. They are currently determining whether this reduced neurogenesis detected at $\mathrm{P} 17$ results in fewer total granule cells in adult mice or whether homeostatic mechanisms are in place to normalize granule cell number over time. Neonatal seizures also enhanced dendritic arborization and altered synaptic input to newborn neurons. Inhibition of the NKCC1 chloride cotransporter with bumetanide suggests that depolarizing GABAergic mechanisms (Markwardt and Overstreet-Wadiche, 2008) play a role in altered neurogenesis after neonatal seizures.

These results presented by Overstreet-Wadiche augment our understanding of how neonatal seizures affect neuronal development and circuit formation (Porter, 2008) and thus potentially contribute to the cognitive deficits and other long-term consequences observed in experimental animals and human patients after repeated seizure activity. This work adds to the increasing appreciation of the age-dependent response of neurogenesis to seizure activity (Porter, 2008), which is highly relevant to the higher incidence of seizure onset in either childhood or late adulthood. For example, whereas experimentally induced seizure activity in adulthood increases SGZ proliferation, seizure activity in old age is not associated with increased SGZ proliferation (Rao et al., 2008). Seizures can also produce aberrant migration and morphology of new neurons that is accompanied by altered synaptic function (Jakubs et al., 2006; Hattiangady and Shetty, 2008; Parent and Murphy, 2008; Zhao and Overstreet-Wadiche, 2008); thus neurogenesis is likely one of many hippocampal abnormalities that contribute to epilepsy and/or cognitive dysfunction.

\section{The schizophrenia susceptibility gene DISC1 regulates adult hippocampal neurogenesis}

In recent efforts to identify molecular mechanisms underlying the progression through stages of neurogenesis, it has become clear that both intrinsic (cell-autonomous) factors as well as extrinsic (microenvironmental) factors are responsible (Ming and Song, 2005; Ge et al., 2007a; Duan et al., 2008). Much is known about factors that regulate early stages of neurogenesis, such as notch signaling, GABA, and glutamate (Duan et al., 2008), but less is known about factors that regulate later stages of neurogenesis.

Using a variety of approaches, Ming and colleagues highlight the first identification of how a known leading candidate gene for mental illness, DISC1 (Disrupted-In-Schizophrenia 1), can regulate distinct developmental processes of newborn neurons in the adult hippocampus. DISC1 is a schizophrenia susceptibility gene whose translocation-induced disruption cosegregates with major psychiatric disease in a Scottish family (Millar et al., 2000). The mouse ortholog is Disc1 (Ma et al., 2002). Although present in the developing and adult brain (Austin et al., 2004), DISC1 appears to plays a key role in neural development (Schurov et al., 2004), influencing cAMP signaling and centrosome and cytoskeletal function (Chubb et al., 2008). Ming and colleagues examined the role of DISC1 in the development of adult-generated hippocampal neurons (Duan et al., 2007; Faulkner et al., 2008) and showed that downregulation of DISC1 by specific short hairpin RNA leads to aberrant cell morphology, accelerated axonal and dendritic development, and mispositioning of new dentate granule cells. In addition, newborn neurons with low DISC1 expression exhibit enhanced excitability and accelerated synapse formation both presynaptically and postsynaptically. Mechanistically, knockdown of NDEL, a binding partner of DISC, mimics some of the DISC1 defects in newborn neurons.

The work presented by Ming highlights the role of DISC1 in orchestrating the tempo of functional neuronal integration in the adult brain and demonstrates the essential role of a susceptibility gene for major mental illness in neuronal development. Additional variants on this approach have also underscored the relationship between DISC1 and schizophrenia (Koike et al., 2006; Kvajo et al., 2008; Pletnikov et al., 2008). Currently, DISC1 interacting molecules are actively being examined for their potential as schizophrenia susceptibility genes (Ikeda et al., 2008) or related behavioral abnormalities (Sakae et al., 2008) and thus may prove 
to be additional targets for fully understanding these intriguing links between schizophrenia and neurogenesis. Although likely no single genetic disruption is responsible for all cases of schizophrenia (Walsh et al., 2008), additional elucidation of how DISC1 and related genes influence neurogenesis and behavior relevant to schizophrenia may provide a jumpstart in learning how to translate these findings from basic research to clinical relevance.

\section{Conclusion/perspective}

These findings highlight new data in the fast-paced field of neurogenesis and emphasize the active and ongoing dissection of dynamic processes that control the development of adultgenerated hippocampal neurons and the function of these new neurons in the adult brain (Fig. 1). The data answer fundamental questions about stem cell biology (Encinas presentation) and identify DISC1 as a novel intrinsic factor that controls maturation of newborn neurons (Ming presentation). The data also highlight work that has identified a new functional role for the neurons in drug reward (Eisch presentation) and neonatal seizure outcome (Overstreet-Wadiche presentation). Last, and most controversial, the work fuels the ongoing debate about the functional role for neurogenesis in learning and depression (Sapolsky, 2004; Kempermann et al., 2008): Cameron's presentation shows intriguing correlative links between learning and neurogenesis, whereas Meltzer's presentation shows that disrupted neurogenesis does not lead to a depressive phenotype. These studies also highlight new methodologies that are allowing more specific questions of hippocampal neurogenesis to be addressed; hopefully, these will be widely used so that their implications can be appreciated throughout the entire field of neuroscience.

When adult-generated neurons were first discovered, it could not have been predicted that these cells would have so many associations with mental illnesses and neurological conditions. The data presented here and elsewhere continue to provide tantalizing connections, but we must remain wary as to whether hippocampal neurogenesis is merely an epiphenomena associated with these illnesses. Often it is argued that the number of new cells in relation to the existing neurons in the granule cell layer is minimal, and thus these cells are likely not important functionally. However, it would seem unlikely that an organ as efficient as the brain would continue to produce these cells if they held no function. It could be that new and old neurons serve different purposes (Cecchi et al., 2001; Ge et al., 2007b; Li et al., 2008) and we are likely just beginning to unravel these differences.

A major caveat of the putative relationship between mental illness and neurogenesis is that most of the findings emerge from basic research on laboratory animals, and little is known about what happens in the human brain. Although technical limitations have restricted previously study to postmortem tissues (Murrell et al., 1996; Eriksson et al., 1998), pioneering work is underway to enable visualization of human neurogenesis in vivo (Manganas et al., 2007). Notable obstacles still remain in being able to label and track stem cells and their offspring in human tissues such as the brain (Schroeder, 2008). However, given recent advances in visualizing neurogenesis and key components of the neurogenic niche in the adult brain as well as tracking of brain circuitry dynamics (Airan et al., 2007a; Lagace et al., 2007; Bulloch et al., 2008; Couillard-Despres et al., 2008), it is likely only a matter of time before we can definitively test links between neurogenesis and brain disorders in the human brain.

\section{References}

Abrous DN, Adriani W, Montaron MF, Aurousseau C, Rougon G, Le Moal M, Piazza PV (2002) Nicotine self-administration impairs hippocampal plasticity. J Neurosci 22:3656-3662.

Abrous DN, Koehl M, Le Moal M (2005) Adult neurogenesis: from precursors to network and physiology. Physiol Rev 85:523-569.

Airan RD, Hu ES, Vijaykumar R, Roy M, Meltzer LA, Deisseroth K (2007a) Integration of light-controlled neuronal firing and fast circuit imaging. Curr Opin Neurobiol 17:587-592.

Airan RD, Meltzer LA, Roy M, Gong Y, Chen H, Deisseroth K (2007b) High-speed imaging reveals neurophysiological links to behavior in an animal model of depression. Science 317:819-823.

Amaral DG, Witter MP (1989) The three-dimensional organization of the hippocampal formation: a review of anatomical data. Neuroscience 31:571-591.

Antonova E, Sharma T, Morris R, Kumari V (2004) The relationship between brain structure and neurocognition in schizophrenia: a selective review. Schizophr Res 70:117-145.

Austin CP, Ky B, Ma L, Morris JA, Shughrue PJ (2004) Expression of Disrupted-In-Schizophrenia-1, a schizophrenia-associated gene, is prominent in the mouse hippocampus throughout brain development. Neuroscience 124:3-10.

Bulloch K, Miller MM, Gal-Toth J, Milner TA, Gottfried-Blackmore A, Waters EM, Kaunzner UW, Liu K, Lindquist R, Nussenzweig MC, Steinman RM, McEwen BS (2008) CD11c/EYFP transgene illuminates a discrete network of dendritic cells within the embryonic, neonatal, adult, and injured mouse brain. J Comp Neurol 508:687-710.

Cameron HA, McKay RD (1999) Restoring production of hippocampal neurons in old age. Nat Neurosci 2:894-897.

Canales JJ (2007) Adult neurogenesis and the memories of drug addiction. Eur Arch Psychiatry Clin Neurosci 257:261-270.

Cecchi GA, Petreanu LT, Alvarez-Buylla A, Magnasco MO (2001) Unsupervised learning and adaptation in a model of adult neurogenesis. J Comput Neurosci 11:175-182.

Chen G, Rajkowska G, Du F, Seraji-Bozorgzad N, Manji HK (2000) Enhancement of hippocampal neurogenesis by lithium. J Neurochem 75:1729-1734.

Chubb JE, Bradshaw NJ, Soares DC, Porteous DJ, Millar JK (2008) The DISC locus in psychiatric illness. Mol Psychiatry 13:36-64.

Couillard-Despres S, Finkl R, Winner B, Ploetz S, Wiedermann D, Aigner R, Bogdahn U, Winkler J, Hoehn M, Aigner L (2008) In vivo optical imaging of neurogenesis: watching new neurons in the intact brain. Mol Imaging 7:28-34.

Drew MR, Hen R (2007) Adult hippocampal neurogenesis as target for the treatment of depression. CNS Neurol Disord Drug Targets 6:205-218.

Duan X, Chang JH, Ge S, Faulkner RL, Kim JY, Kitabatake Y, Liu XB, Yang CH, Jordan JD, Ma DK, Liu CY, Ganesan S, Cheng HJ, Ming GL, Lu B, Song H (2007) Disrupted-In-Schizophrenia 1 regulates integration of newly generated neurons in the adult brain. Cell 130:1146-1158.

Duan X, Kang E, Liu CY, Ming GL, Song H (2008) Development of neural stem cell in the adult brain. Curr Opin Neurobiol 18:108-115.

Dupret D, Fabre A, Döbrössy MD, Panatier A, Rodríguez JJ, Lamarque S, Lemaire V, Oliet SH, Piazza PV, Abrous DN (2007) Spatial learning depends on both the addition and removal of new hippocampal neurons. PLoS Biol 5:e214.

Eisch AJ (2002) Adult neurogenesis: implications for psychiatry. Prog Brain Res 138:315-342.

Eisch AJ, Mandyam CD (2007) Adult neurogenesis: can analysis of cell cycle proteins move us "Beyond BrdU”? Curr Pharm Biotechnol 8:147-165.

Eisch AJ, Barrot M, Schad CA, Self DW, Nestler EJ (2000) Opiates inhibit neurogenesis in the adult rat hippocampus. Proc Natl Acad Sci U S A 97:7579-7584.

Encinas JM, Vaahtokari A, Enikolopov G (2006) Fluoxetine targets early progenitor cells in the adult brain. Proc Natl Acad Sci USA 103:8233-8238.

Encinas JM, Vazquez ME, Switzer RC, Chamberland DW, Nick H, Levine HG, Scarpa PJ, Enikolopov G, Steindler DA (2008) Quiescent adult neural stem cells are exceptionally sensitive to cosmic radiation. Exp Neurol 210:274-279.

Eriksson PS, Perfilieva E, Björk-Eriksson T, Alborn AM, Nordborg C, Peterson DA, Gage FH (1998) Neurogenesis in the adult human hippocampus. Nat Med 4:1313-1317. 
Faulkner RL, Jang MH, Liu XB, Duan X, Sailor KA, Kim JY, Ge S, Jones EG, Ming GL, Song H, Cheng HJ (2008) Development of hippocampal mossy fiber synaptic outputs by new neurons in the adult brain. Proc Natl Acad Sci U S A 105:14157-14162.

Floresco SB, Blaha CD, Yang CR, Phillips AG (2001a) Modulation of hippocampal and amygdalar-evoked activity of nucleus accumbens neurons by dopamine: cellular mechanisms of input selection. J Neurosci 21:2851-2860.

Floresco SB, Todd CL, Grace AA (2001b) Glutamatergic afferents from the hippocampus to the nucleus accumbens regulate activity of ventral tegmental area dopamine neurons. J Neurosci 21:4915-4922.

Ge S, Pradhan DA, Ming GL, Song H (2007a) GABA sets the tempo for activity-dependent adult neurogenesis. Trends Neurosci 30:1-8.

Ge S, Yang CH, Hsu KS, Ming GL, Song H (2007b) A critical period for enhanced synaptic plasticity in newly generated neurons of the adult brain. Neuron 54:559-566.

Geuze E, Vermetten E, Bremner JD (2005) MR-based in vivo hippocampal volumetrics. 2. Findings in neuropsychiatric disorders. Mol Psychiatry 10:160-184.

Gould E, McEwen BS, Tanapat P, Galea LA, Fuchs E (1997) Neurogenesis in the dentate gyrus of the adult tree shrew is regulated by psychosocial stress and NMDA receptor activation. J Neurosci 17:2492-2498.

Gould TJ (2006) Nicotine and hippocampus-dependent learning: implications for addiction. Mol Neurobiol 34:93-107.

Groenewegen HJ, Vermeulen-Van der Zee E, te Kortschot A, Witter MP (1987) Organization of the projections from the subiculum to the ventral striatum in the rat. A study using anterograde transport of Phaseolus vulgaris leucoagglutinin. Neuroscience 23:103-120.

Hattiangady B, Shetty AK (2008) Implications of decreased hippocampal neurogenesis in chronic temporal lobe epilepsy. Epilepsia 49 [Suppl 5]:26-41.

Holmes GL, Gairsa JL, Chevassus-Au-Louis N, Ben-Ari Y (1998) Consequences of neonatal seizures in the rat: morphological and behavioral effects. Ann Neurol 44:845-857.

Holsboer F (2008) How can we realize the promise of personalized antidepressant medicines? Nat Rev Neurosci 9:638-646.

Ikeda M, Hikita T, Taya S, Uraguchi-Asaki J, Toyo-oka K, Wynshaw-Boris A, Ujike H, Inada T, Takao K, Miyakawa T, Ozaki N, Kaibuchi K, Iwata N (2008) Identification of YWHAE, a gene encoding 14-3-3epsilon, as a possible susceptibility gene for schizophrenia. Hum Mol Genet 17:3212-3222.

Jakubs K, Nanobashvili A, Bonde S, Ekdahl CT, Kokaia Z, Kokaia M, Lindvall O (2006) Environment matters: synaptic properties of neurons born in the epileptic adult brain develop to reduce excitability. Neuron 52:1047-1059.

Kee N, Teixeira CM, Wang AH, Frankland PW (2007) Preferential incorporation of adult-generated granule cells into spatial memory networks in the dentate gyrus. Nat Neurosci 10:355-362.

Keller SS, Roberts N (2008) Voxel-based morphometry of temporal lobe epilepsy: an introduction and review of the literature. Epilepsia 49:741-757.

Kelley AE, Domesick VB, Nauta WJ (1982) The amygdalostriatal projection in the rat-an anatomical study by anterograde and retrograde tracing methods. Neuroscience 7:615-630.

Kempermann G, Jessberger S, Steiner B, Kronenberg G (2004) Milestones of neuronal development in the adult hippocampus. Trends Neurosci 27:447-452.

Kempermann G, Krebs J, Fabel K (2008) The contribution of failing adult hippocampal neurogenesis to psychiatric disorders. Curr Opin Psychiatry 21:290-295.

Kim SJ, Lee KJ, Shin YC, Choi SH, Do E, Kim S, Chun BG, Lee MS, Shin KH (2005) Stress-induced decrease of granule cell proliferation in adult rat hippocampus: assessment of granule cell proliferation using high doses of bromodeoxyuridine before and after restraint stress. Mol Cells 19:74-80.

Koike H, Arguello PA, Kvajo M, Karayiorgou M, Gogos JA (2006) Disc1 is mutated in the $129 \mathrm{~S} 6 / \mathrm{SvEv}$ strain and modulates working memory in mice. Proc Natl Acad Sci U S A 103:3693-3697.

Kronenberg G, Reuter K, Steiner B, Brandt MD, Jessberger S, Yamaguchi M, Kempermann G (2003) Subpopulations of proliferating cells of the adult hippocampus respond differently to physiologic neurogenic stimuli. J Comp Neurol 467:455-463.

Kvajo M, McKellar H, Arguello PA, Drew LJ, Moore H, MacDermott AB,
Karayiorgou M, Gogos JA (2008) A mutation in mouse Disc1 that models a schizophrenia risk allele leads to specific alterations in neuronal architecture and cognition. Proc Natl Acad Sci U S A 105:7076-7081.

Lagace DC, Yee JK, Bolaños CA, Eisch AJ (2006) Juvenile administration of methylphenidate attenuates adult hippocampal neurogenesis. Biol Psychiatry 60:1121-1130.

Lagace DC, Whitman MC, Noonan MA, Ables JL, DeCarolis NA, Arguello AA, Donovan MH, Fischer SJ, Farnbauch LA, Beech RD, DiLeone RJ, Greer CA, Mandyam CD, Eisch AJ (2007) Dynamic contribution of nestinexpressing stem cells to adult neurogenesis. J Neurosci 27:12623-12629.

Li Y, Luikart BW, Birnbaum S, Chen J, Kwon CH, Kernie SG, Bassel-Duby R, Parada LF (2008) TrkB regulates hippocampal neurogenesis and governs sensitivity to antidepressive treatment. Neuron 59:399-412.

Lodge DJ, Grace AA (2006) The hippocampus modulates dopamine neuron responsivity by regulating the intensity of phasic neuron activation. Neuropsychopharmacology 31:1356-1361.

Lucassen PJ, Heine VM, Muller MB, van der Beek EM, Wiegant VM, De Kloet ER, Joels M, Fuchs E, Swaab DF, Czeh B (2006) Stress, depression and hippocampal apoptosis. CNS Neurol Disord Drug Targets 5:531-546.

Ma L, Liu Y, Ky B, Shughrue PJ, Austin CP, Morris JA (2002) Cloning and characterization of Disc1, the mouse ortholog of DISC1 (Disrupted-inSchizophrenia 1). Genomics 80:662-672.

Malberg JE, Eisch AJ, Nestler EJ, Duman RS (2000) Chronic antidepressant treatment increases neurogenesis in adult rat hippocampus. J Neurosci 20:9104-9110.

Manganas LN, Zhang X, Li Y, Hazel RD, Smith SD, Wagshul ME, Henn F, Benveniste H, Djuric PM, Enikolopov G, Maletic-Savatic M (2007) Magnetic resonance spectroscopy identifies neural progenitor cells in the live human brain. Science 318:980-985.

Markwardt S, Overstreet-Wadiche L (2008) GABAergic signalling to adult generated neurons. J Physiol 586:3745-3749.

McCabe BK, Silveira DC, Cilio MR, Cha BH, Liu X, Sogawa Y, Holmes GL (2001) Reduced neurogenesis after neonatal seizures. J Neurosci 21:2094-2103.

Meltzer LA, Yabaluri R, Deisseroth K (2005) A role for circuit homeostasis in adult neurogenesis. Trends Neurosci 28:653-660.

Mignone JL, Kukekov V, Chiang AS, Steindler D, Enikolopov G (2004) Neural stem and progenitor cells in nestin-GFP transgenic mice. J Comp Neurol 469:311-324.

Millar JK, Wilson-Annan JC, Anderson S, Christie S, Taylor MS, Semple CA, Devon RS, Clair DM, Muir WJ, Blackwood DH, Porteous DJ (2000) Disruption of two novel genes by a translocation co-segregating with schizophrenia. Hum Mol Genet 9:1415-1423.

Ming GL, Song H (2005) Adult neurogenesis in the mammalian central nervous system. Annu Rev Neurosci 28:223-250.

Murrell W, Bushell GR, Livesey J, McGrath J, MacDonald KP, Bates PR, Mackay-Sim A (1996) Neurogenesis in adult human. Neuroreport 7:1189-1194.

Nixon K, Crews FT (2002) Binge ethanol exposure decreases neurogenesis in adult rat hippocampus. J Neurochem 83:1087-1093.

Noonan MA, Choi KH, Self DW, Eisch AJ (2008) Withdrawal from cocaine self-administration normalizes deficits in proliferation and enhances maturity of adult-generated hippocampal neurons. J Neurosci 28:2516-2526.

Parent JM (2007) Adult neurogenesis in the intact and epileptic dentate gyrus. Prog Brain Res 163:529-540.

Parent JM, Murphy GG (2008) Mechanisms and functional significance of aberrant seizure-induced hippocampal neurogenesis. Epilepsia 49 [Suppl 5]:19-25.

Parent JM, Elliott RC, Pleasure SJ, Barbaro NM, Lowenstein DH (2006) Aberrant seizure-induced neurogenesis in experimental temporal lobe epilepsy. Ann Neurol 59:81-91.

Pittenger C, Duman RS (2008) Stress, depression, and neuroplasticity: a convergence of mechanisms. Neuropsychopharmacology 33:88-109.

Pletnikov MV, Ayhan Y, Nikolskaia O, Xu Y, Ovanesov MV, Huang H, Mori S, Moran TH, Ross CA (2008) Inducible expression of mutant human DISC1 in mice is associated with brain and behavioral abnormalities reminiscent of schizophrenia. Mol Psychiatry 13:173-186, 115.

Porter BE (2008) Neurogenesis and epilepsy in the developing brain. Epilepsia 49 [Suppl 5]:50-54.

Rao MS, Hattiangady B, Shetty AK (2008) Status epilepticus during old age is not associated with enhanced hippocampal neurogenesis. Hippocampus 18:931-944. 
Sahay A, Hen R (2007) Adult hippocampal neurogenesis in depression. Nat Neurosci 10:1110-1115.

Sakae N, Yamasaki N, Kitaichi K, Fukuda T, Yamada M, Yoshikawa H, Hiranita T, Tatsumi Y, Kira J, Yamamoto T, Miyakawa T, Nakayama KI (2008) Mice lacking the schizophrenia-associated protein FEZ1 manifest hyperactivity and enhanced responsiveness to psychostimulants. Hum Mol Genet 17:3191-3203.

Santarelli L, Saxe M, Gross C, Surget A, Battaglia F, Dulawa S, Weisstaub N, Lee J, Duman R, Arancio O, Belzung C, Hen R (2003) Requirement of hippocampal neurogenesis for the behavioral effects of antidepressants. Science 301:805-809.

Sapolsky RM (2000) Glucocorticoids and hippocampal atrophy in neuropsychiatric disorders. Arch Gen Psychiatry 57:925-935.

Sapolsky RM (2004) Is impaired neurogenesis relevant to the affective symptoms of depression? Biol Psychiatry 56:137-139.

Schroeder T (2008) Imaging stem-cell-driven regeneration in mammals. Nature 453:345-351.

Schurov IL, Handford EJ, Brandon NJ, Whiting PJ (2004) Expression of disrupted in schizophrenia 1 (DISC1) protein in the adult and developing mouse brain indicates its role in neurodevelopment. Mol Psychiatry 9:1100-1110.

Shors TJ, Townsend DA, Zhao M, Kozorovitskiy Y, Gould E (2002) Neurogenesis may relate to some but not all types of hippocampal-dependent learning. Hippocampus 12:578-584.

Snyder JS, Hong NS, McDonald RJ, Wojtowicz JM (2005) A role for adult neurogenesis in spatial long-term memory. Neuroscience 130:843-852.

Taepavarapruk P, Floresco SB, Phillips AG (2000) Hyperlocomotion and increased dopamine efflux in the rat nucleus accumbens evoked by elec- trical stimulation of the ventral subiculum: role of ionotropic glutamate and dopamine D1 receptors. Psychopharmacology (Berl) 151:242-251.

Tashiro A, Makino H, Gage FH (2007) Experience-specific functional modification of the dentate gyrus through adult neurogenesis: a critical period during an immature stage. J Neurosci 27:3252-3259.

Toda H, Hamani C, Fawcett AP, Hutchison WD, Lozano AM (2008) The regulation of adult rodent hippocampal neurogenesis by deep brain stimulation. J Neurosurg 108:132-138.

Totterdell S, Smith AD (1989) Convergence of hippocampal and dopaminergic input onto identified neurons in the nucleus accumbens of the rat. J Chem Neuroanat 2:285-298.

Walsh T, McClellan JM, McCarthy SE, Addington AM, Pierce SB, Cooper GM, Nord AS, Kusenda M, Malhotra D, Bhandari A, Stray SM, Rippey CF, Roccanova P, Makarov V, Lakshmi B, Findling RL, Sikich L, Stromberg T, Merriman B, Gogtay N, et al. (2008) Rare structural variants disrupt multiple genes in neurodevelopmental pathways in schizophrenia. Science 320:539-543.

West CH, Weiss JM (2005) A selective test for antidepressant treatments using rats bred for stress-induced reduction of motor activity in the swim test. Psychopharmacology (Berl) 182:9-23.

Yamaguchi M, Saito H, Suzuki M, Mori K (2000) Visualization of neurogenesis in the central nervous system using nestin promoter-GFP transgenic mice. Neuroreport 11:1991-1996.

Zhao CS, Overstreet-Wadiche L (2008) Integration of adult generated neurons during epileptogenesis. Epilepsia 49 [Suppl 5]:3-12.

Zhao C, Deng W, Gage FH (2008) Mechanisms and functional implications of adult neurogenesis. Cell 132:645-660. 